REFERENCES

DHSS (1980) Organizational and management problems of mental illness hospitals. Report of a working group.

Norman, A. (1982) A Shared Responsibility. Centre for the Policy on Ageing.

Post, F. Levy, R. (1982) Psychiatry of Late Life. London: Blackwells.

Royal College of Psychutrists (1979) Guidelines for collaboration between geriatric physicians and psychiatrists in the care of the elderly. Bulletin of the Royal College of Psychiatrists, November, pp. 168-69.

\section{Guidelines for teaching psychology to students of psychiatry \\ DeAR SiRs}

Last year the Bulletin (April 1982, 6, 54-6) carried an article, 'Sciences Basic to Psychiatry: AUTP Guidelines', which contained a footnote to the effect that the teaching of psychology as applied to psychiatry was the subject of a joint working party of the College and the British Psychological Society. As Chairman of the Joint Standing Committee of the College with the British Psychological Society, I have asked to write to you to amplify the footnote.

The position, in fact, is that this Joint Standing Committee did produce a document some five years ago on the teaching of psychology to students of psychiatry. On the advice of the College members of the Joint Standing Committee at that time, this was forwarded to the College's Court of Electors who, we were advised, in turn forwarded it to the AUTP. The latter have presumably made what use of the document they chose, and this is reflected in the currently published 'Guidelines'. The Joint Standing Committee is reasonably content with the Guidelines now issued, although it would have liked to have seen: (a) some amplification of the relationship between the basic sciences and their applications; and (b) a more definitive statement on the psychotherapies.

However, there is not at present any working party of the Joint Standing Committee in existence, nor is one planned. There is a survey of teaching requirements under way by the Professional Affairs Board of the British Psychological Society, and the results will no doubt eventually be available to the Joint Standing Committee and thence to the AUTP.

It may also be of interest to know that the Joint Standing Committee's incoming Chairman-Dr J. Jancar (the Chairmanship alternates annually between the College and the Society)-is proposing that a small conference of invited representatives from the two bodies should be set up to consider issues of mutual interest and concern. Teaching Guidelines and syllabuses might well be one item, and the Joint Standing Committee would welcome suggestions for others.

\section{Broadmoor Hospital}

Crowthorne, Berks

\section{Training for senior registrars with special interest in psychiatry of old age}

\section{DeAr Sirs}

More or less every week there are advertisements of vacancies for the post of psychiatrist with a special interest in psychiatry of old age. There appear to be large numbers of senior registrars in adult psychiatry who want to have some training in psychogeriatrics. There are a limited number of posts which have been specified for training in psychogeriatrics. In my view, senior registrars who want to become psychogeriatricians need some guidance about the type of training they should try to look for. There is an article by $\mathrm{Dr}$ D. J. Jolley, 'Psychiatrist into psychogeriatrician' (Bulletin, November 1976, 11-13) which is worth reading.

During some recent meetings with other senior registrars, I had the feeling that there were some questions to be answered about the training needs and I would try to answer some of the questions.

1. Should one have one's first posting as senior registrar in adult psychiatry or in psychogeriatrics when one has already decided to become a psychogeriatrician? 1 feel that one should complete the training in adult psychiatry first before starting full time in psychogeriatrics. As regards the time limit, six months to one year's training in psychogeriatrics should be sufficient.

2. Are day or two-day attachments over long periods sufficient? I do not think that this is a good idea because one cannot become fully involved in the different aspects of services for the elderly.

3. Should one work full time in geriatrics for three to six months? Theoretically, it appears to be an excellent idea, but there are some practical problems. In my view a psychogeriatrician needs to have or acquire a good knowledge of internal medicine, but there is no need to try to become a geriatrician as well.

4. Should one have attachments full-time or part-time with EEG departments or CAT scan departments? In my view full-time attachments for even short periods may not be necessary. As a consultant psychogeriatrician one needs to interpret results or even interpret the recording which one could do by acquiring sound theoretical knowledge and some knowledge of practical aspects of these investigations.

5. Should one do domiciliary visits? I think one should do domiciliary visits for the experience although senior registrars are not entitled to payment at the moment, but this should not be an obstacle because experience is necessary.

6. Should one spend some time with the community services for the elderly? The answer is 'yes'. One could visit and liaise with Part III Homes, EMI Home or even private nursing homes who admit elderly patients.

7. Must you do research to become a consultant? In my view research is not a must to become a consultant, but in 